\title{
Identidades en tensión, lo indígena y lo nacional en las experiencias cotidianas mbyá
}

\author{
Noelia Enriz \\ CONICET, Buenos Aires, Argentina. Email: nenriz@yahoo.com.ar
}

Resumen: El presente artículo pretende aportar elementos a la problematización del modo en que las identidades nacionales e indígenas se han vinculado y consolidado en el caso argentino, tomando como referencia a las poblaciones guaraníes de la provincia de Misiones. Analizamos ciertas experiencias de campo y reflexionamos sobre aspectos de la tensión histórica de estas identidades a partir de relatos y fuentes documentales. Finalmente abordamos la discusión de cómo los estados se vinculan en la actualidad con las identidades indígenas a través de políticas específicas.

Palabras clave: identidad, mbyá, Argentina.

\section{Identities in tension, indigenous and national in mbyá everyday experiences}

\begin{abstract}
The aim of this paper is to provide information to the problematization of how national and indigenous identities have been connected and consolidated in the case of Argentina, with reference to the Guarani people of the province of Misiones. We analyzed some field experiences and aspects of the historical tension of these identities from stories and documentary sources. Finally we approached the discussion of how States are linked today with indigenous identities through specific policies.
\end{abstract}

Key words: identity, mbyá, Argentine.

\section{Identidades em tensão, o indígena e o nacional nas experiências cotidianas mbyá}

Resumo: O presente artigo visa fornecer informações para a problematização de como as identidades nacionais e indígenas que tenham sido ligados e consolidadas, no caso da Argentina, com referência ao povo Guarani da província de Misiones. Nós analisamos algumas experiências de campo e refletir sobre os aspectos da tensão histórica dessas identidades a partir de histórias e fontes documentais. Finalmente, aproximou-se da discussão de como os estados estão ligados, hoje, com identidades indígenas, através de políticas específicas.

Palavras-chave: identidade, mbyá, Argentina. 


\section{Introducción}

La consolidación de la Republica Argentina como un territorio con identidad nacional ha sucedido a espaldas de las identidades indígenas que lo habitaban y habitan. Y, aunque en los últimos años la existencia indígena se ha vuelto más visible, en ciertos cánones se los sigue denominando como sujetos del pasado. Los esfuerzos de pensar la identidad nacional han tenido relaciones dispares con la imagen del gaucho, en ocasiones denostado y en otras reivindicado, y lo mismo con los migrantes de distintas latitudes, a quienes se invitó a incorporarse a dicho modelo más allá de sus particularidades. La imagen de lo indígena, no atravesó esos vaivenes alternadamente reivindicatorios, ya que se dio por hecho su inexistencia a la hora de constituir la nación.

Sostenemos que en los últimos años lo indígena se ha vuelto más visible a partir de ciertos elementos. Por un lado de leyes especificas y centralmente de la incorporación un artículo en la Constitución Nacional que reconoce la preexistencia (Art. 75 inciso 17), la promulgación de ciertas leyes (Ley Nacional $N^{\circ} 24.956$ de Censo Aborigen; Ley Nacional $\mathrm{N}^{\circ}$ 25.517 de Restitución de Restos Aborígenes; Ley Derechos de Difusión de Derechos Indígenas y la reciente Ley Nacional 26160 de Tierras y Registro Nacional de Comunidades).

En este nuevo escenario, lo indígena no se integra a la idea de nación, sino que es visto como algo previo que vuelve a emerger. Así también, desde las identidades indígenas se construyen diversas miradas sobre lo nacional, especialmente a partir del establecimiento de instituciones escolares.

En este texto nos proponemos abordar esta tensión de identidades indígenas y nacionales a partir de cierto escenario específico, el que presenta la zona dónde habitan los guaraníes en el noreste argentino. Si bien en términos generales podría pensarse que entre las poblaciones indígenas de argentina y el estado nacional existen por definición tensiones que deben discutirse y atenderse especialmente, el caso guaraní presenta ciertas particularidades: que lo componen una serie de parcialidades que establecen adscripciones identitarias particulares, que habitan territorios de varios países (Argentina, Brasil, Paraguay, Bolivia), que su patrón de poblamiento no se corresponde con el modelo político administrativo de dichos territorios, las distintas estrategias de movilidad por le terreno, entre otras. Además, profundizaremos estos elementos desde la lectura de registros de campo particulares, realizados a partir de interacciones con niños, lo que supone una dimensión específica de estas temáticas y la incorporación en un campo disciplinar puntual dentro de la antropología actual.

\section{La cuestión indígena en la región}

La población mbyá guaraní de Misiones (ver Mapa 1) se encuentra en un contexto muy particular de tensión entre territorio, identidad étnica y 
nacional, ya que es un territorio dónde los debates por la identidad forman parte de lo cotidiano. Esto se debe a varias razones. En primer lugar, por ser Misiones un territorio fronterizo, con mucha más frontera internacional que interna, frontera internacional además con un país de habla portuguesa -Brasil- y con otro dónde el español es una segunda lengua -Paraguay-. Cabe agregar además que esta frontera, habitada a todos sus márgenes por población guaraní, ha sido la zona de mayor impacto del proyecto jesuítico, a través de la instalación de reducciones. En segundo lugar porque ha sido una de las más dinámicas regiones en el proceso de por el cual la nación argentina incorporó grandes grupos de población procedente de diferentes regiones europeas, especialmente del éste. (Gorosito, 2000)

Si bien en términos generales podría pensarse que entre las poblaciones indígenas y los estados nacionales existen por definición tensiones que deben discutirse y atenderse especialmente, el caso guaraní presenta ciertas particularidades algunas de las cuales adelantamos anteriormente: que lo componen una serie de parcialidades diferentes que dan lugar a adscripciones identitarias específicas, que habitan territorios de varios estados nacionales, que su patrón de poblamiento estaría asociado a una serie de elementos -bioma, religión, etc.- asociados a diversas estrategias de movilidad por el territorio.

La población guaraní habita en una amplia región de América del Sur que abarca zonas de Argentina, Bolivia, Brasil y Paraguay. En total, en toda la región y considerando todas las parcialidades existentes (Aché, Avá o Ñanadeva, Mbyá y $\mathrm{Pa}_{-}$o Kaiowa) suman más de cien mil personas. En Argentina habitan en las provincias de Salta y Misiones, en esta última, dónde desarrollamos nuestro trabajo de campo, habitan unas seis mil quinientas personas de la parcialidad mbyá, habitan en núcleos ${ }^{1}$ en el área rural y son hablantes de la lengua homónima. (Grumberg, 2008)

Las condiciones de vida de los distintos núcleos mbyá en la provincia de Misiones presentan grandes diferencias, centradas especialmente en los vínculos que éstos tengas con las instituciones del Estado. En términos generales, un tercio de lo núcleos tiene acceso a la escolaridad, una menor proporción tiene acceso a planes de asistencia social y al sistema provincial de salud. Si bien las primeras experiencias escolares datan de comienzos de los años ochenta, la ley de Educación Intercultural Bilingüe es del año 2005. Generalmente, las relaciones mas fluidas con el estado están asociadas a la presencia de poblaciones urbanas y de caminos en las cercanías de los núcleos. Un tema que merece atención especial es la cuestión territorial. Si bien cómo vimos, la población mbyá de Misiones habita en el área rural, las extensiones de territorio varían y también las dimensiones del grupo. Un elemento ampliamente generalizado (con muy escazas excepciones) es la carencia de títulos de propiedad. Por último, la subsistencia de estas poblaciones está asegurada a partir de diferentes elementos, desde la caza y la recolección hasta el empleo en trabajos rurales temporarios.

La investigación doctoral, de que es fruto este texto, se ha desarro- 
llado en diferentes períodos de trabajo de campo prolongado de cohabitación entre los años 2003 y 2009, financiada por el CONICET (Consejo Superior de Investigaciones en Ciencia y Tecnología de Argentina). La misma tuvo foco en tres zonas de la provincia, a las que llamaremos Yabotí, Centro Oeste y Kuña Pirú, se ubican respectivamente en el límite con Brasil, con Paraguay y el centro de la provincia (ver mapa al final del texto). Trabajamos en estas tres regiones diferentes con el objeto de dar cuenta de un modo representativo de los diversos elementos que influyen en la organización social y los modos diferentes en que se experimentan elementos identitarios en cada caso. Intentamos abordar la diversidad de situaciones que enfrenta la población mbyá con respecto a la escuela, visitando un núcleo sin acceso al sistema escolar, otro con escuela pública de simple turno y otro con escuela privada doble turno. También nos enfrentamos a tres situaciones distintas de relación con el español: uno con escasísimas competencias en español, otro con ciertas herramientas intermedias y otro con gran desarrollo del bilingüismo.

El objetivo central de la investigación ha sido relevar las experiencias cotidianas de los niños mbyá, por tanto, el trabajo de campo ha sido en el ámbito doméstico, en cohabitación con las familias, en distintos períodos del año y períodos prolongados.

\section{Metodología y aproximaciones teóricas}

El interés de la antropología como disciplina científica, por la infancia como grupo de indagación específico transita un período de gran vigor en América latina en la última década. Diversos autores se focalizan en indagaciones donde las perspectivas de los niños están en el centro de la escena (Colangelo 2003; Cohn 2001; Donoso 2005; Enriz 2006; Hecht 2004; García Palacios 2005; Larriq 1993; Leal Ferreira 2002; Nunes 1999; Szulc 2000; Remorini 2004; Tasinari 2001; Trpin 2004). Estas investigaciones recuperan el enfoque etnográfico para acercase a problemáticas muy variadas como los conocimientos religiosos, las diversas apropiaciones lingüísticas, temas de salud, etcétera.

En este marco hemos comenzado una indagación con niños en distintos núcleos de la comunidad mbyá-guarani de la provincia de Misiones, en Argentina. Las temáticas de interés han ido transformándose, pero los sujetos centrales de la indagación han sido niños de diversas edades, aunque centralmente hemos focalizados sobre aquellos entre tres y once años. Esta franja etaria se corresponde con lo que en lengua nativa se denomina kiringüe o kiri' $i$. Son sujetos que tienen grandes niveles de independencia respecto de sus progenitores en su circulación por el territorio. A su vez, establecen relaciones de grupalidad constituyendo grupos de juego con otros niños, con los que recorren y reconocen diversos elementos del entorno desde animales o plantas hasta zonas de acceso o inaccesibilidad. Por otra parte, son considerados aún como niños, en tanto no han atravesado los rituales de pasaje que los constituirían en sujetos adultos. (Enriz y García Palacios 2008) 
La investigación que da sustento a este texto se ha realizado en distintas zonas de la provincia de Misiones, en estancias de campo de permanencia y cohabitación prolongada con las familias de los niños involucrados.

En este análisis consideramos con Barth "que los grupos étnicos son categorías de adscripción e identificación que son utilizadas por los actores mismos y tienen, por tanto, la característica de organizar interacción entre los individuos. Intentamos relacionar otras características de los grupos étnicos a este aspecto fundamental. En segundo término, todos los ensayos aplican un punto de vista generativo al análisis; en lugar de trabajar por medio de una tipología de las formas de los grupos étnicos y sus relaciones, nos proponemos explorar los diferentes procesos que al parecer participan en la generación y conservación de los grupos étnicos. En tercer y último lugar, para observar estos procesos, desviamos el foco de la investigación de la constitución interna y de la historia de los grupos étnicos para centrarlo en los límites étnicos y su persistencia” (1979: 10). Es decir, nos proponemos dar cuenta de los modos de adscripción, pero antes de las categorías en uso en las reflexiones cotidianas sobre esa adscripción. Además, nos interesa dar cuenta de los procesos que generan identidades de modo contrastativo, de modo que estaremos pensando en los elementos que constituyen exclusiones identitarias y carencias, a modo de límites de la interpretación de dichas categorías.

\section{Identidades y reflexiones cotidianas}

Las experiencias cotidianas de los niños mbyá suceden en el marco de núcleos comunitarios donde la identidad se manifiesta como un elemento sobre entendido. Es decir, es un contexto de baja confrontación con otros modos identitarios. No obstante, como ya señalamos el contexto local es de gran profusión de aspectos identitarios.

Los sujetos que habitan dentro de los núcleos, quienes residen permanente y variablemente, comparten una categoría de adscripción identitaria a esa parcialidad guaraní. Sostienen esto centralmente a partir de su adscripción y de ser admitidos, o adscriptos por los otros a esta misma instancia. En sus reflexiones cotidianas, en el uso de una lengua común y en la presencia de cierta ritualidad religiosa podrían sostenerse estos aspectos de la identidad. (Barth, 1976)

No obstante, y como es factible considerar, las dimensiones de esa adscripción, es decir del uso de esa lengua, la practica de esa religiosidad, etc. son aspectos que se expresan de modo diferencial en lugares con características específicas. Para aclarar un poco este punto, me refiero concretamente a la expresión de estos elementos identitarios en zonas donde se expresa cierta confrontación u oposición a otras identidades, o por el contrario zonas dónde esas identidades se refuerzan aisladamente de la oposición a otras. 
En los núcleos que habitan en la Reserva de Biósfera Yabotí ${ }^{2}$ la confrontación con otros modos culturales de expresar cotidianamente identidades se hace muy poco probable, dada la escaza circulación de sujetos por aquellas zonas. Se trata en concreto de regiones dónde la caza y recolección son estrategias centrales de supervivencia, no existe acceso a la escolaridad y los pueblos mas cercanos se encuentran a distancias considerables.

Por otro lado, contrariamente a la escena descripta anteriormente, en aquellos núcleos que disponen en las inmediaciones de rutas internacionales, como es el caso de los núcleos ubicados en las inmediaciones de la Ruta Nacional $\mathrm{N}^{\mathrm{o}} 12^{3}$ la expresión de lo identitario reconoce un modelo de confrontación y/o semejanza con otras identidades que circulan por esas zonas. Se trata en estos casos de núcleos con acceso a la escolaridad y distintos recursos de movilidad, contacto con pueblos y subsistencia sostenida a partir de trabajo asalariado masculino y planes sociales.

Estas dos formas de vivir la identidad mbyá, son a su vez afirmadas desde los propios sujetos que constituyen este grupo identitario, ambas como modalidades posibles. Esta contrastación nos permite destacar que si bien un aspecto actualmente relevante de lo identitario es el uso cotidiano de la lengua nativa, ser considerado bilingüe o monolingüe no supone una desvalorización identitaria. Lo mismo podría decirse de otros aspectos como el religioso.

De modo que, un modelo de estudio generativo (Barth, 1976) de estas identidades nos permitiría considerar cómo estos elementos que a simple vista pueden suponer notables distanciamientos en las experiencia cotidianas son interpretados por los sujetos involucrados en la adscripción identitaria de modo tal que aparecen como irrelevantes.

En tal sentido, es importante advertir que las diferencias en los grupos a lo largo de la provincia de Misiones, y más aún si consideramos los otros países involucrados, permiten relevar modalidades cotidianas de experimentar esta identidad de forma muy diversa y que a su vez, estas modalidades son adscriptas por los sujetos y avaladas por los otros como parte de los modos de ser mbyá posibles.

Es importante destacar aquí que en los distintos contextos los vínculos con otras identidades (nacionales, migrantes, indígenas, etc) varían. Un registro de campo de un núcleo ubicado en la frontera entre Argentina y Brasil nos permitirá considerar de que modo se producen ciertas contrastaciones identitarias y que aspecto del ser mbyá son destacados por los propios miembros del grupo:

"En la mañana en el Opy Camilo (hombre jóves +/- 18 años) habló de nuevo sobre los Pongue (dijo que son Kaingang y que Pongue es como los Mbyá les dicen), dijo que suelen robarles en la Rodoviaria de Itapiranga [terminal de ómnibus]. Antes, ellos se quedaban a dor- 
mir ahí y ahora no se quedan más. También dijo que a ellos les robaron dos radios y comida, muchas veces. Contaba que ellos viven acá cerca, en Brasil, en una zona de campo sin monte y que ahí no siembran, por tanto pasan bastante hambre. Como suelen robar, además no consiguen trabajo en la colonia. Dice Camilo que los brasileros los llaman mugre, que a él una vez le dijeron así y él respondió que era Mbyá" (Yaboti 12|06|05)

Estas pequeñas tensiones relatadas en el ámbito doméstico, en conversaciones informales, motivadas por la propia lógica de la conversación y no estimuladas específicamente por la entrevista, nos permiten advertir de qué modo la cuestión identitaria se manifiesta.

Aparecen algunos elementos para pensar la adscripción positiva a cierta identidad indígena y la negatividad colocada sobre cierta otra. En este caso se hace referencia a una población indígena con la que ocasionalmente estos sujetos han compartido situaciones -en ocasiones conflictivas- en ámbitos públicos en el territorio de Brasil. En dichas ocasiones, los accionares de los sujetos involucrados, pongue y mbyá, son percibidas en términos identitarios. En primer término se coloca una denominación a esta población y se refiere, explicado como el modo en que "nosotros les decimos a ellos”.

Además, se refiere instancias delictivas dónde han sufrido sustracciones como un conflicto identitario, en tanto se expresa que los pongue se dedican al delito, y que le roban a los mbyá. En esta misma línea de argumentación se vinculan las dificultades de acceso a recursos naturales para al subsistencia, concretamente la ausencia de monte (Selva paranaense), como un elemento que distorsiona la posibilidad de acceder a los recursos de subsistencia.

Aquí se tensionan desde la perspectiva de los sujetos involucrados, las tensiones entre grupos, descriptas y conceptualizadas a partir de un modelo identitario que reduce y sintetiza matices.

Tal como sostiene en su análisis Brubacker y Cooper (2000) no nos proponemos conceptualizar teóricamente esta categoría, sino en cambio pensar las dimensiones concretas que estas categorías tienen para los sujetos a la hora de reflexionar sobre si mismos y los otros.

Si bien en estas reflexiones, Camilo refiere a los Kaingang, es importante destacar que ignoramos por completo si se trata concretamente de miembros de esta población o no. Simplemente nos interesa profundizar la significatividad que las categorías identitarias manifiestan para estos sujetos a la hora de pensar lo cotidiano.

Es relevante destacar aquí, de que modo las identidades nacionales se solapan y hasta la misma idea de frontera nacional queda al margen en estas argumentaciones. El hecho de que las cosas sucedan en Brasil o Ar- 
gentina no aparece como elemento relevante, en cambio se destaca la incidencia en las experiencias cotidianas de estas identidades de las estrategias de subsistencia, y en tal medida de ciertos biomas fructíferos o estrategias de producción adecuadas.

Consideramos en tanto, como lo destaca Hirsch para el caso del Noreste argentino y Sur boliviano donde habitan los Ava guaraní, que "Para los guaraníes de Argentina, una frontera relativamente abierta y permeable permite el cruce de bagaje simbólico y permite también la conexión con los pares del otro lado de la frontera, cuyas prácticas políticas participativas refuerzan sus propios proyectos políticos” (Hirsch: 1997: 6).

En otros contextos cotidianos, dónde algunos niños reflexionan sobre sus propios roles se manifiestan matices al interior del ser mbyá, como concepto identitario general. Una de estas manifestaciones es de gradualidad, es decir, sujetos que expresan grados distintos al interior de esa conceptualización identitaria. Hemos registrado estas diferenciaciones en núcleos dónde habitaban personas que no adscriben a la identidad indígena, que se referencian en identidades nacionales o bien en pertenencias a sectores productivos (campesino, por ejemplo). Lo valioso de estos registros es que permiten dar cuenta de las tensiones respecto de a definición identitaria a partir de sitios dónde no está dada la adscripción por habitan al interior de una comunidad, sino que estas potencialidades se imbrican aleatoriamente.

En este marco, ciertos conocimientos infantiles, especialmente aquellos referidos al medio y, por ejemplo los alimentos disponibles que pueden consumirse, eran indicados como “muy mbyá” los niños que poseían esos saberes. Concretamente, tres hermanitos pequeños que compartían conmigo la semilla interna del fruto seco del Pindó (Syagrus romanzoffiana) indicándome cómo debía consumirlo y especialmente que “el gusanito también se come” (Centro Oeste 29|11|05). El conocimiento de esos elementos, la invitación a consumirlos y l acceso a las estrategias de cómo obtener esos productos era conceptualizado en términos de gradaciones identitarias de mayor envergadura.

Lo mismo podría decirse en los contextos áulicos de las instituciones escolares de dicho núcleo (y de otros de similares característica) respecto de quienes conocen mayor cantidad de vocablos de la lengua mbyá. Ese saber es altamente valorado y reconocido por los pares, sin importar el nivel de bilingüismo en otras lenguas como el castellano o el guaraní del Paraguay. En este caso, en que la identidad se pondera a partir de conocimientos específicos relativos a cierta especificidad, podríamos inferir la relevancia de un valor conceptualizado como cultural, ya que en términos religiosos se considera cierta pureza espiritual a partir del manejo exclusivo de la lengua mbyá. Un anciano para establecer mejor vínculo con los dioses debe comunicarse solamente en lengua mbyá en sus interlocuciones cotidianas y luego en la lengua religiosa durante la ceremonia específica, pero el uso de otras lenguas es considerado negativamente. 
La reflexión respecto del lenguaje entre los mbyá y las particularidades del guaraní han sido abordadas de diversas maneras por renombrados especialistas (Cadogan 1992, Melia 1995, Dietrich 2002), sin que la cuestión se agotara.

Por último, hemos recuperado menciones dónde la identidad indígena era descripta negativamente, tales serían las referencias a modelos higiénicos específicos. Un chico no mbyá refiere "Ellos no se bañan porque son paisanos" (Centro Oeste 30|11|05), haciendo referencia con paisanos a otra modalidad de denominar lo indígena en dicho ámbito.

A través de estas referencias, intentamos mostrar de que modo diversos elementos de lo identitario se construye en los relatos cotidianos de jóvenes y adultos a través de elementos de contrastación y adscripción que se ensamblan de diversos modos y se sustentan en reflexiones sobre experiencias concretas de los sujetos.

Tal como las diferencias de representación respecto de lo lingüístico aportan elementos para expresar valoraciones sobre lo identitario, otras experiencias cotidianas permiten considerar variables diferenciales, aunque sobre las mismas no hayamos registrado reflexiones verbalizadas.

En los dos fragmentos de registro que colocamos a continuación veremos de qué modo actúa la cuestión identitaria marcando distancias entre los sujetos, simétricamente a la consolidación de cierto grupo.

"Hay un chico que no es mbyá, que vive aquí porque su mamá se junto en pareja con un paisano. Juega en el patio de la escuela con otros niños mucho más chiquitos que él. Los chiquitos van sobre él, se tiran a piso y se empujan hasta rodar por un desnivel del suelo. Las luchas duran mucho rato, los jugadores no suelen salir "vencidos”, pero en cierto momento se cansan y dejan éste juego para hacer otra cosa” (Perutí 25|11|05)

"Las dos chicas de la clase de $6^{\text {to. }}$ año quedaron solas en el aula. Aurelia es una chica muy retraída y que no se siente a gusto en el lugar, ella no quería hablar solo me contó que su mamá se junto con un mbyá y por eso ella vive ahí. Esto fue en el marco de la clase, los chicos mbyá dijeron que ella no salía nunca ni siquiera de la casa, que ella no se halla y preferiría irse” (Perutí 10|06|08)

En los casos analizados, la adscripción identitaria coadyuva a la constitución de grupos al interior de los núcleos de la comunidad. De este modo, se van dando diversas adscripciones, además de la adscripción general a lo mbyá. En los dos fragmentos de registros que colocamos anteriormente queda de manifiesto el modo en que ciertos niños que conviven con esas identidades, pero no adscriben ni son adscriptos lidian con la posibilidad de construir sus propios modos de incorporación a los grupos. En el primero de los registros, el niño jugaba cotidianamente con los más pe- 
queños y no encontraba puentes de vinculación grupal con los niños de su misma edad, algo que no se manifestaba en los demás niños de su edad que eran mbyá. En el segundo de los fragmentos, la niña había encontrado vínculos con otras mujeres, particularmente con otras niñas de su misma edad y compañeras de grado, pero no lograba avanzar en ese vínculo por fuera del ámbito escolar, y permanecía dentro de su casa.

En estas escenas de niños no mbyá viviendo en entornos comunitarios indígenas se manifiestan, desde nuestra perspectiva algunos elementos que constituyen lo identitario en tanto modo de ser.

Como sostiene Elizabeth Pissolato (2006), los estudios tradicionales sobre el modo de ser guaraní han tendido a considerar un sistema que organizaría diversos aspectos, entre los que ha estado incluida la cuestión del territorio, ya que el teko fue definido como el lugar donde podemos ser. En el último tiempo los estudios sobre territorialidad han estado más interesados por considerar de la perspectiva histórica los elementos asociados a la movilidad. No obstante, algunos elementos que podríamos asociar al modo de ser se vislumbran desde el abordaje identitario:

"Alicia, comienza a hablar de si misma. Ella fue criada por su abuela, porque la mamá y el papá se dejaron antes de que ella naciera. Ambos son mbyá y su mamá vive en Ka’a kupe (...) cuando se cambió la dejo con la abuela. Ellas dos vivieron siempre juntas, y solas. Cuando ella era chica la abuela la retaba porque ella era muy “retobada”. (Perutí 10|06|08)

En el fragmento se manifiesta la movilidad por el territorio, como parte de las prácticas cotidianas del ser mbyá, especialmente cuando esas prácticas están asociadas a la posibilidad de atravesar territorios mbyá, es decir núcleos establecidos por la comunidad dónde cualquier mbyá puede residir. Aquí se encuentra un meollo interesante en el esquema de adscripción identitaria y a su vez de consolidación espacial en el territorio.

Aquellos espacios territoriales dónde se asienta la comunidad mbyá, a los que nosotros denominamos núcleos, aparecen como tierras habitables por los mbyá. Es decir, la sola adscripción étnica y la adscripción por los otros, permite alojarse y habitar en estos lugares. Esa posibilidad de residencia está asociada a la posibilidad de manifestar ese ser mbyá.

En cierta ocasión me sucedió un hecho que ilustra claramente las dimensiones de esta adscripción. Regresé para hacer trabajo de campo a un lugar dónde habitualmente lo hacía, siempre con aval del anciano. Al llegar, fui a visitarlo y me comentó que el cacique estaba en su casa -nunca habíamos coincidido porque éste rea un hombre con muchas ocupaciones en la capital provincial-y que podría acercarme a conocerlo y presentarme. Fui hasta su casa y saludé a su mujer, a quien si conocía de otras estadías. Al saludarlo comencé a explicarle que quería quedarme por unos días, el cacique comenzó a hablarme de que eso no era posible porque ese era un 
lugar solamente para gente mbyá. La esposa del cacique intervino en la conversación diciéndole "no va a quedarse a vivir, solamente unos días, siempre lo hace”. El hombre me explico entonces que en ocasiones hay personas que quiere quedarse a vivir allí, pero que eso solo es posible para gente mbyá. En esta escena se expresa de que modo lo identitario configura un escenario territorial, dónde la adscripción y la adscripción por los otros actúa como elemento determinante.

\section{Identidades y políticas públicas}

Del mismo modo que al interior de la comunidad indígena la adscripción funciona como un elemento que posibilita ciertas acciones, la cuestión identitaria es tomada por los organismos de gobierno como un confuso elemento a la hora del diseño de políticas.

Como considera Aravena "la identidad étnica no puede ser definida mediante por un conjunto de características físicas, psicológicas y culturales objetivas. Pero sí por la construcción social y política de tales características, permitiendo la diferenciación de grupos denominados étnicos. Desde un punto de vista subjetivo, el sentimiento de pertenencia étnica y el hecho de compartir una herencia cultural común parecieran ser los principales criterios de definición de los grupos étnicos como categoría de diferenciación social. Desde esta perspectiva, la etnicidad es considerada como una forma de organización social capaz de constituirse y de transformarse en la interacción de los grupos sociales, designando así los procesos a través de los cuales los individuos se identifican y son identificados por otros, atribuyéndose identidades particulares, sin permanecer atados a una entidad fija definida desde el exterior” (Aravena:2003:94).

La presencia del Estado y su consolidación territorial a lo largo de la historia ha estado asociada a las políticas de vinculación que se diera con las diversas poblaciones. Estos vínculos adquirieron características particulares en los diversos períodos políticos que el propio Estado atravesara. Pero una característica en los procesos de crecimiento económico ha sido la administración de políticas públicas que se ocupen de aquellas poblaciones que por diversas razones no sean directas beneficiarias de las mieses productivas. (Ansolabehere, 2003; Huaylupo Alcázar, 1999)

La política de Estado expresa las propiedades o las cualidades del Estado en cierta época. Esto no supone que sean meros deseos del estado en sí, sino la "dirección que se impone activamente en la acción estatal como expresión o en nombre de intereses generales” (Grasi, 2003:23) Así como en ciertos períodos la calidad de pobre, o desocupado se volvieron relevantes en estos campos de acción, la cuestión indígena ha sido frecuentemente pasible de políticas por parte del estado.

En Argentina, estas políticas tienen particularidades en diversos períodos históricos, pero sin duda su surgimiento ha estado asociado a las 
políticas del Estado de Bienestar. En el caso misionero, de que nos ocuparemos aquí, esta particularidad no ha sido tan significativa. Al menos, en las instancias vinculadas a las políticas públicas destinadas a población indígena. Es que, la presencia indígena en Misiones tuvo un escueto reconocimiento en el desarrollo histórico de la provincia.

Las fuentes de circulación vulgar (periódicos y documentos recuperados de archivo) relativas al período anterior a 1950 no dan cuenta de la presencia indígena, del mismo modo que cierto corpus histórico (Amable y Dorhman, 2003; Schiavoni, 1998).

Pero ya desde mediados de los años ' 50 , dónde comienzan a hacerse menciones, en los documentos de gobierno se hace manifiesta la necesidad de generar un ente administrativo relativo a la regulación de las condiciones de vida de la población indígena (decretos 324/1954 y 2366/1957), con particular énfasis en su protección.

La primera expresión estatal de este interés, se vehiculizó a través de un censo. Este primer mapeo poblacional, realizado en el año 1966, se enmarco en el Decreto 3998/65, que ordenara la realización del Censo Nacional Indígena (Novick, 2002: 13). La cifra obtenida entonces fue de 1.500 habitantes. $^{4}$

No obstante, la presencia indígena en si misma tampoco aseguraba nada, ya que los medios de comunicación gráficos provinciales hasta mediados de 1980 advertían permanentemente sobre la inevitable extinción de estas poblaciones. A modo de ejemplo: el 22 de agosto de 1976, el periódico El Territorio titulaba "Entre la extinción y la supervivencia: grupo de aborígenes de Colonia Lanusse”. En esta instancia, al desconocimiento se sumaba el deseo normalizador: "Se precisó que los indígenas pertenecen a la raza guaraní, sin acusar mayor evolución en relación a su grado cultural anterior (...) Y que se verán obligados a abandonar su hábitat porque el progreso es cruel y el blanco es el enemigo natural de lo autóctono, desde el indio hasta el pez" (El Territorio, 14/08/1970).

En este mismo sentido, se expresa destaca su "paupérrima" condición de vida, señalando que no producen de forma intensiva. Dicha situación es atribuida por el periodista a dos razones: que no están habituados a hacerlo y que, por ser un terreno muy pedregoso, no cuentan con las maquinarias utilizadas en esa zona. Esta circunstancia los lleva a "subsistir de lo poco que ofrece la naturaleza circundante: larvas, insectos, mamíferos, frutas, peces” (El Territorio, 14/08/1970). Estas expresiones en los medios masivos enuncian el desconocimiento sobre las condiciones de vida y las formas de subsistencia que los mbyá habían utilizado ancestralmente. Esa "paupérrima" modalidad de subsistencia ha sido registrada desde las primeras etnografías sobre el grupo, y puede considerarse que representa la forma de subsistencia de los pueblos de esta zona (Susnik, 1983).

Las políticas públicas destinadas a estas poblaciones han sido diver- 
sas, a pesar del corto plazo de tiempo de que se trata. Podemos distinguir tres momentos diferentes de propuestas e implementación de experiencias de vinculación y asistencia de las poblaciones mbyá por parte del Estado.

Si bien hasta 1970 las políticas públicas destinadas a población indígena en Misiones se reducían a censos poblacionales, a éstas las sucedieron grandes propuestas de intervención, que serán el objeto de análisis de las próximas páginas. A este período, enmarcado entre 1978 y 1983 lo indicamos como el primer momento en que se realizaron políticas públicas para población indígena en Misiones. Un segundo momento, ha estado marcado por el primer reclamo masivo de las poblaciones indígenas respecto de los planes de asistencia, promediando la mitad de la primera década del siglo XXI. Un tercer momento, es el actual, dónde las demandas y las políticas encuentran ciertos niveles de estabilidad. (Enriz, 2010)

Solo nos detendremos en la primera de estas propuestas, por su ambigua relación con o identitario. En ella, una vez elegido el núcleo dónde se desarrollaría la política pública, se proponía la “aculturación programática”. El programa se proponía “posibilitar la paulatina integración de los aborígenes en el proceso de desarrollo provincial favoreciendo la participación de los mismos” (Fuente: Acción de gobierno 1976-1983). Se estimulaba la inclusión en el mercado y la formación para esta participación, para lo cual era necesario "incentivar al máximo el deseo de progreso, participación y toma de decisión por parte de la comunidad en todo lo que respecta a los subprogramas” (Amable y Dohmann, 2003: 26). Quedar por fuera suponía atraso, así como participar sin la sistematicidad necesaria para originar proyectos de lucro. Esto queda plasmado en la evaluación de una docente, quien, respecto de los frutales, sostiene que "se observa sobreproducción por falta de adecuada comercialización” (Ibídem: 31). La sedentarización, la producción agrícola intensiva y la correspondiente comercialización de dichos productos eran etapas del desarrollo de esta política pública destinada a poblaciones indígenas.

Por otro lado, para pensar las dinámicas de lo identitario es relevante considerar que en cada caso, las políticas han dejado a cargo de las propias comunidades la potestad de definir quien es o no miembro de dicho grupo y que a su vez, han dado reconocimiento a todos los grupos que se manifestaran con dicha identidad y no fueran negados por otros. En todos los casos se ha tratado de población que habitaba en núcleos, en zonas no urbanas.

\section{Conclusiones}

La relevancia de las identidades, a la hora de constituir un escenario de vínculos que permitan sostener las particularidades de los sujetos se hace evidente en las prácticas cotidianas, en los registros que recuperamos. La relevancia específica de las identidades indígenas en las actuales coyun- 
turas, merece análisis específicos y reiterados, dada la vertiginosidad de las transformaciones.

Hemos intentado dar cuenta de cómo en la consolidación territorial del Estado Argentino, las identidades indígenas ha jugado un papel de absoluta subalternidad. También vimos de que modo esas identidades han permanecido y se constituyen cotidianamente, frente a otros modelos de adscripción y a las tensiones que algunas políticas públicas les ofrecen.

Como sostiene Briones “a pesar de la homogeneidad declamada, el crisol que se toma como anclaje sociológico innegable de la nacionalidad nunca terminó de fundir del todo el «tipo argentino» esperado. Por eso, en el país que se ha jactado históricamente de ser el enclave europeo en y de Latinoamérica, los indios nunca terminan de desaparecer y la ausencia de negros contrasta con la abundancia de cabecitas negras. Por eso, en el país abierto a «todos los hombres del mundo que quieran habitar el suelo argentino», los hijos de inmigrantes de países limítrofes se siguen viendo como bolivianos o peruanos que extreman las inadecuaciones atribuidas a ciertos nacionales, aunque permitiendo externalizarlas” (2004: 86)

Es decir, la obcecada pretensión estatal-gubernamental de sostener una identidad homogénea frente a la argentinidad, en la que no estaban articulados sujetos específicos como los pobladores originarios del territorio, parece encontrar su límite en la necesidad actual de diseñar políticas específicas para contemplar estas especificidades.

Del mismo modo, la necesidad de reconocimiento de estas identidades por parte del Estado, se vuelve una demanda a la hora de hacer carne las políticas diseñadas y, especialmente, de recuperar el valor de los pactos internacionales en esta materia.

Como sostiene Gorosito (2008), nos encontramos en un período en que el reconocimiento de la preexistencia obliga a pensar nuevamente las conceptualizaciones identitarias que parecen ligar lo indígena con modelos de organización de lo doméstico en el plano familiar, y no con perspectivas de largo plazo, históricamente constituidas y sostenidas a partir de formas consolidadas de expresión de sus particularidades.

El encausamiento de las diferencias a partir de cánones identitarios preestablecidos, solo da lugar a subterfugios que no colaboran con la recreación de las prácticas identitarias, cosifican lo indígena y dejan quieta a la cultura. Para poder dar cuenta de las particularidades de la construcción de lo identitario en las experiencias indígenas será necesario recuperar muchas formas de pertenencia admitidas por los grupos e intervenir de modo tal de no definir anticipadamente que elementos deben constituirlas. 


\section{Mapa 1}

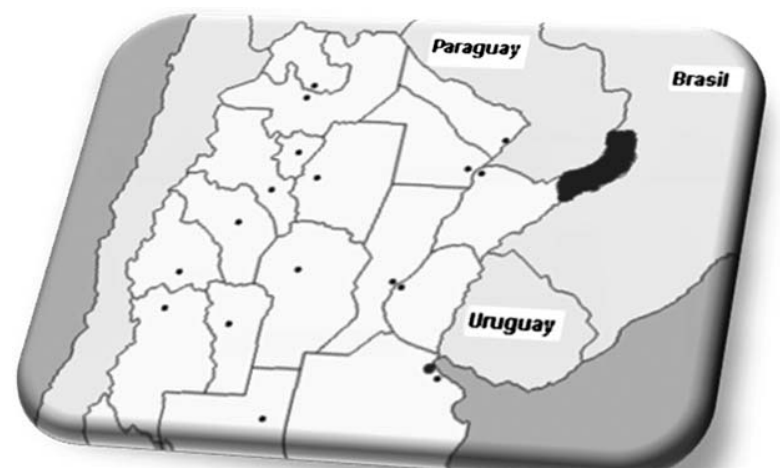

En negro destacada la provincia de Misiones, Argentina. 
Polis, Revista de la Universidad Bolivariana, Volumen 9, $N^{\circ}$ 27, 2010

\section{Notas}

${ }^{1}$ Denominamos núcleos a los distintos grupos de familias que se condensan en diversas regiones de la provincia y que forman parte de la comunidad mbyá. Esta categoría podría ser análoga a tekoa.

${ }^{2}$ Según el portal de UNESCO (www.portal.unesco.org) las reservas de biosfera son sitios reconocidos en el marco del Programa sobre el Hombre y la Biosfera, que demuestran la relación entre conservación y desarrollo sostenible. En el caso argentino son administrados por el Comité MAB, que depende de la Secretaria de Ambiente y Desarrollo Sustentable de la Nación, y se encarga de la protección de la biodiversidad.

${ }^{3}$ La Ruta Nacional $N^{\circ} 12$ es conocida como Ruta del Mercosur porque une Argentina con Brasil. A su vez es eje de varios puntos turísticos relevantes, el más destacado las Cataratas de Iguazú.

${ }^{4}$ Fuentes extraoficiales hacen mención a un censo anterior, en 1956, en el cual se habrían contabilizado apenas 300 individuos. No hemos tenido acceso a ese relevamiento. 


\section{Bibliografía}

Amable, María Angélica y Dohmann Karina (2003), La educación bilingüe de los guaraníes den Misiones: La experiencia de Fracrán y Perutí, Instituto Superior “Antonio Ruiz de Montoya” Centro de Investigaciones Históricas “Guillermo Furlong”.

Ansolabehere, Karina (2003), "Provincias, instituciones e incertidumbre: el derrotero de la descentralización de las políticas sociales en Argentina”. En: Revista Mexicana de Sociología, Vol. 65, No. 3 (Jul. - Sep., 2003), pp. 629-662. Universidad Nacional Autónoma de México.

Barth, Frederic (1976) [1969], Los grupos étnicos y sus fronteras. La organización social de las diferencias culturales. Fondo de Cultura Económica, México D. F.

Bartolomé, Miguel Alberto (2006), "Los laberintos de la identidad: procesos identitarios en las poblaciones indígenas”. Avá (Posadas) [online]. Aug. 2006, no.9 [cited 18 August 2008], p.28-48. 4.

Briones Claudia. (2004), Construcciones de aboriginalidad en Argentina. Société suisse des Américanistes / Schweizerische AmerikanistenGesellschaft Bulletin 68, 2004, pp. 73-90.

Cadogan, León (1992), Diccionario Mbyá-Guaraní - Castellano, Edición preparada por Friedl Grünberg bajo la dirección de Bartomeu Melià, CEADUC - CEPAG, Asunción.

Ídem(1997), Ayvu-Rapyta. Textos míticos de los Mbya-guaraní del Guairá. Fundación León Cadogan. CEADUC. CEPAG, Asunción.

Clastres, Piere (1993), La palabra luminosa. Mitos y cantos sagrados de los guaraníes. Ediciones del Sol. Buenos Aires.

Cohn, Clarice (2000), “Crescendo como um Xikrin: uma análise da infância e do desenvolvimento infantil entre os Kayapó-Xikrin do Bacajá”. En Revista de Antropologia 43/2.

Colángelo, María Adelaida (2003), “La mirada antropológica sobre la infancia. Reflexiones y perspectivas de abordaje”, Mesa: Infancias y juventudes. Pedagogía y formación. Seminario Internacional La formación docente entre el siglo XIX. Mimeo, Buenos Aires.

Dietrich, Wolf (2002), “Guaraní criollo y guaraní étnico en Paraguay, Argentina y Brasil”. En: Mily Crevels, Simon van de Kerke, Sérgio Meira \& Hein van der Voort (eds.), Current Studies on South American Languages [Indigenous Languages of Latin America, 3], p. 31-41. Research School of Asian, African, and Amerindian Studies (CNWS), Leiden. 
Donoso, Carla (2005), “Buscando Las Voces De Los Niños/As Viviendo Con Vih: Aportes Para Una Antropologia De La Infancia”. I Congreso Latinoamericano de Antropología. Rosario, Argentina. 11 al 15 de Julio.

Enriz, Noelia y García Palacios Mariana (2008), “Deviniendo Kuña va’era”. En: Mujeres indígenas, Silvia Hirsch (Coordinadora). (pp. 205-230) ISBN:978-950-786-656-2, Ed. Biblos. Buenos Aires.

Enriz, Noelia (2006), “Etnografía del juego infantil en la comunidad Mbyaguaraní de la provincia de Misiones”. Tesis de Licenciatura. Facultad de Filosofía y Letras, UBA. ISBN-10: 950-29-0000-6 / ISBN-13: 978-95029-0000-1.

García Palacios, Mariana (2005), “¿Qué puede decir la antropología acerca del punto de vista de los niños en un estudio sobre religión?”. Ponencia presentada en $1^{\circ}$ Congreso de la Asociación Latinoamericana de Antropología. Rosario.

Gorosito Kramer, Ana María (2000), “Monumentos Jesuíticos de Misiones (Argentina): disputas sobre el patrimonio”. Ponencia en: $1^{\circ}$ Congreso virtual Naya. http://naya.org.ar/congreso2000/ponencias/Ana_Gorosito.htm

Ídem (2008), “Convenios y leyes: La retórica políticamente correcta del Estado”. En: Cuadernos de Antropología Social No 28, pp. 51-65, 2008 Facultad de Filosofía y Letras. Universidad de Buenos Aires. ISSN: 03273776.

Grassi, Estela (2003), Política y problemas sociales en la sociedad neoliberal. La otra década infame. Espacio Editorial, Buenos Aires.

Grumberg, Georg (Coord.), Bartomeu Melià (Ed.) Guarani Retã (2008), Povos Guarani na Fronteira Argentina, Brasil e Paraguai. CTI, 2008. Mapa (100x69cm) e Livro Explicativo (24p).

Hecht, Ana Carolina (2004), “Educación intercultural bilingüe en las comunidades wichí de Ramón Lista (Formosa): procesos de apropiación, resistencia y negociación”. Tesis de Licenciatura en Ciencias Antropológicas - Facultad de Filosofía y Letras, Universidad de Buenos Aires, Buenos Aires.

Henry, Jules y Zunia (1974), Doll Play Of Pilagá Indian Children. New York. Vintage Books.

Huaylupo Alcázar, Juan Alberto (1999), “Las políticas públicas en un contexto de privatización de la práctica social del Estado”. En: Revista Mexicana de Sociología, Vol. 61, No. 4 (Oct.-Dic., 1999), pp. 55-72. Universidad Nacional Autónoma de México.

Hymes Dell, Hathaway (1962), The ethnography of speaking. Anthropology 
and human behavior. Anthropological Society of Washington, Washington, D.C.

Larriq, Marcelo (1993), Ipyt_ma construcción de la persona entre los Mbyaguarani. EditorIal Universitaria. Universidad Nacional de Misiones.

Leal Ferreira, María Kawal (2002), “Tupi-Guarani Apocalyptic Visions of Time and the Body”. En: Journal of Latin American Anthropology. 7(1):128169.

Mauss, Marcel (1967), Manuel d'etnographie. Éditions Payot \& Rivales. Paris.

Meliá, Bartolomeu (1981), “El ‘modo de ser guarani’ en la primera documentación Jesuítica (1594 - 1639)”. En: Revista de Antropología.Vol. 24.

Ídem (1995), Elogio de la lengua Guarani. Centro de Estudios Paraguayos Antonio Guasch. Asunción.

Novick S. (2002), "Legislación referida a censos y estadísticas en la argentina: 1854-1991”. Ponencia presentada en el XIII Word Congress of the International Economic History Association (IEHA) Session $N^{\circ} 80$. "Estatistical and cartographic information in State and market building process, 18th. 20th century”. Buenos Aires, 22-26 de Julio de 2002.

Nunes Machado Pereira, Angela María. (1999), A sociedades das crianças A'uwe-Xavante. Instituto de Innovação Educacional, Ministerio da Educação, Lisboa.

Pires, Flavia. (2007), “Ser adulta e pesquisar crianças: explorando possibilidades metodológicas na pesquisa antropológica”. En: Revista De Antropologia, São Paulo, Usp, 2007, V. 50 N 1 . Rev. Antropol. [online]. 2007, v. 50, n. 1 [cited 2008-12-11], pp. 225-270. ISSN 0034-7701. doi: 10.1590/S0034-77012007000100006.

Pissolato, Elizabeth de Paula (2006), “A Duração da Pessoa mobilidade, parentesco e xamanismo mbya” (guarani). Tese de doutorado apresentada ao Programa de Pós-Graduação em Antropologia Social do Museu Nacional da Universidade Federal do Rio de Janeiro.

Remorini, Carolina (2004), “Emãe nde Kypy-I Re! (Cuidá por tu hermanita!). Un análisis del papel de las interacciones infantiles en el proceso de endoculturación Mbya”. Actas del Congreso Argentino de Antropología Social. Villa Giardino: Edición en CD de la Universidad Nacional de Córdoba.

Ruiz, Irma (1998), “Apropiaciones y estrategias políticas: una interpretación sobre la dinámica de cambio musical en contexto ritual”. En: Latin American Music Review / Revista de Música Latinoamericana, Vol. 19, No. 2. (Autumn - Winter, 1998), pp. 186-202. 
Santana de Oliveira, Marisa (2005), “Nhanhembo’e: infância, educação e religião entre os Guarani de M’Biguaçu, SC”. Cadernos de Campo, n 13: 75-89.

Schiavoni Graciela (1998), Colonos y ocupantes; parentesco, reciprocidad y diferenciación social en la frontera agraria de Misiones. Editorial Universitaria de la UNaM, Posadas.

Silva Noelli Francisco (1993), “Sem Teko não há Tekoa (Em Busca de um Modelo Etnoarqueológico da Aldeia e da Subsistência Guarani e sua Aplicação a uma Área de Domínio no Delta do Rio Jacuí-RS)”. Tese do Mestre em História Ibero-America. Universidade Federal de Porto Alegre.

Susnik, Branislava (1988), Etnohistoria del Paraguay. Etnohistoria de los Chaqueños y de los guaraníes. Bosquejo histórico. Suplemento antropológico (Vol. XXXIII - N² 2). Asunción.

Szulc Andrea (2000), “La construcción social de la niñez en Chacabuco (Provincia de Buenos Aires)”. VI Congreso Argentino de Antropología Social. Mar del Plata. Argentina.

Tassinari, Antonella (2001), ”Escola indígena: novos horizontes teóricos, novas fronteiras de educação”. In: Lopes Da Silva, Aracy; Leal, Mariana Kawall Ferreira (Orgs.). Antropologia, História e Educação - A questão indígena e a escola. São Paulo: Global, 2001, p. 44-70.

Trpin, Verónica (2004), Aprender a ser chilenos. Identidad, trabajo y resistencia de migrantes en el Alto Valle de Río Negro. Editorial Antropofagia, Buenos Aires.

Wilde, Guillermo (2007), “De la depredación a la conservación. Génesis y evolución del discurso hegemónico sobre la selva misionera y sus habitantes”. Revista Ambiente \& sociedade, janeiro-junho, año/vol. 10, n 001. Asociaçao Nacional de pos- Graduaçao e Pesquisa em Ambiente e Sociedade. Campinas Brasil. (pp. 87-106)

Recibido: 09.10.10

Aceptado: 17.11.10 